312066005209865 


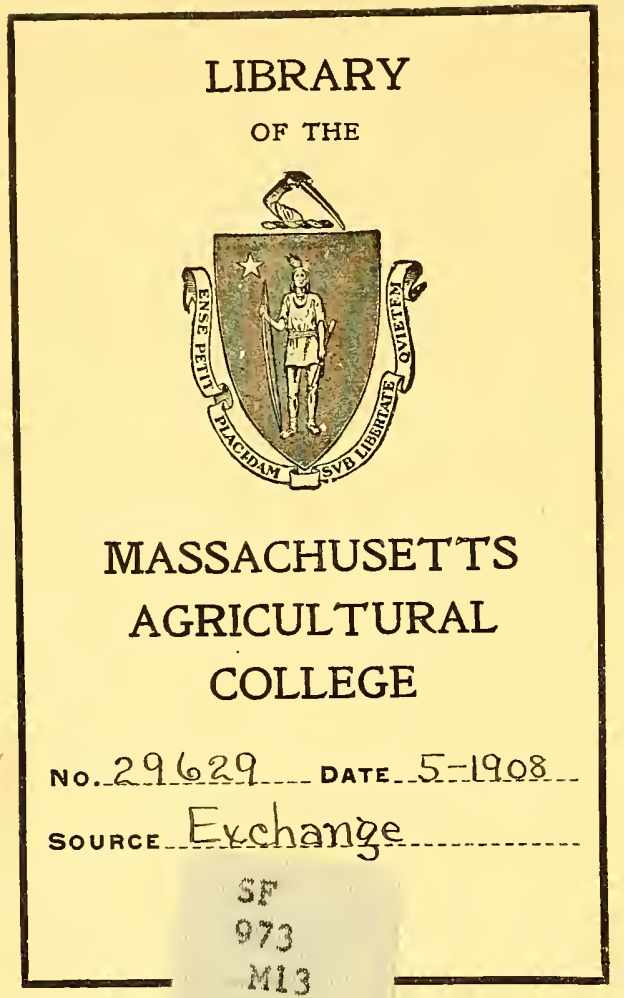


This book may be kept out

T W O W E E K

only, and is subject to a fine of TWO CENTS a day thereafter. It will be due on the day indicated below.
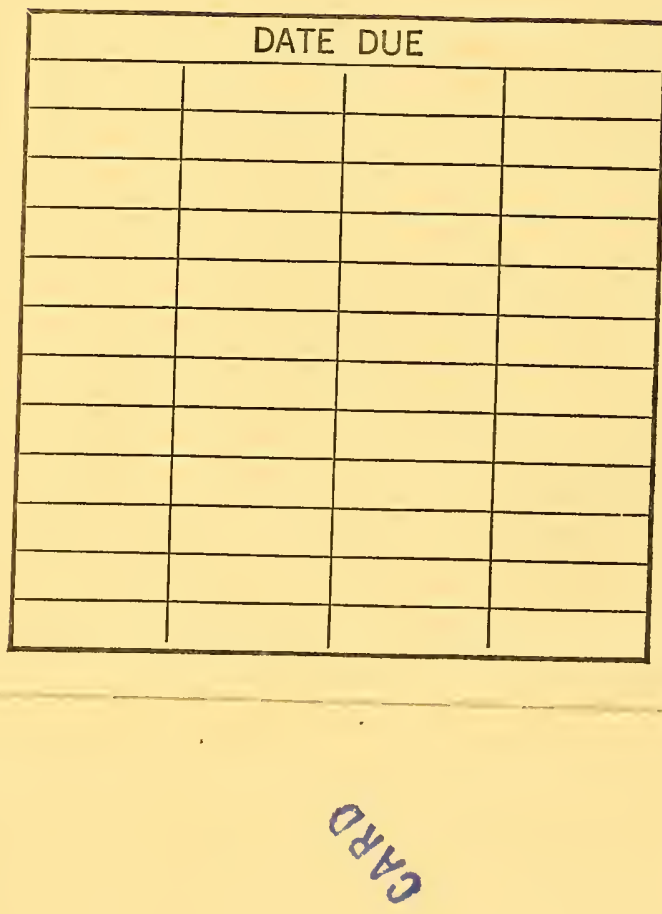
Digitized by the Internet Archive in 2010 with funding from Boston Library Consortium Member Libraries 


\section{STUDIES ON HOG CHOLERA}

CHARLES MCCLINTOCK

CHARLES H. BOXMEYER

J. J. SIFFER

(From the Department of Experimental Medicine, Parke, Davis \& Co., Detroit)

The Journal of Infectious Diseases, Vol. II, No. 2, March I, I905, pp. 351-374 


$$
\begin{aligned}
& 619.94 \\
& M 13
\end{aligned}
$$




\title{
STUDIES ON HOG CHOLERA.*
}

\author{
Charles T. McClintock, M.D., Charles H. Boxmeyer, A.B., \\ AND J. J. SiFFER, M.D. \\ (From the Department of Experimental Medicine, Parke, Davis \& Co., Detrout.)
}

I.

\section{THE VALUE OF AGGLUTINATION FOR THE DIAGNOSIS OF HOG CHOLERA.}

Charles T. MCClintock, Charles H. Boxmeyer and J. J. Siffer.

The close resemblance of the hog cholera to the typhoid bacillus, and the somewhat similar symptoms and course of the diseases caused by them, suggested that agglutination might prove as valuable a method of diagnosis for hog cholera as it has proven for typhoid. The first application of the agglutination test for this purpose was made by Dinwiddie, ${ }^{1}$ of the Arkansas Experiment Station. The few cases he tested all gave a negative reaction. No hog cholera bacilli were isolated from the outbreak which furnished this material. Dawson, ${ }^{2}$ Smith, ${ }^{3}$ and others have made experiments with the blood of vaccinated rabbits which show the reaction often in high dilutions. We are unaware of any other experiments than those of Dinwiddie with the blood of diseased hogs.

The material with which we worked was obtained from the following seven epizootics:

1. Hastings, Mich.-The disease first appeared in slaughter-house hogs fed on refuse. It was communicated by them to hogs on an adjoining lot separated only by a wire fence. From there it spread to neighboring farms. Practically all the animals exposed contracted the d:sease. The mortality, including animals of all ages, was 50 to 60 per cent. The animals that survived apparently thrived. Autopsy showed considerable variation in the pathological appearances of the individual animals examined. Practically all the lesions described for hog cholera were found. The intestinal changes as

* Received for publication January 14, 1905.

1 Jour. Comp. Med. and Vet. Areh., 1900, 21, p. 528.

2 New York Med. Jour., February 20, 1897, 65, p. 253.

3 Jour, Med. Research, 1903, 91, p. 270. 
a rule were quite marked. A marked hyperemia only; small deep ulcers, large diphtheric patches, areas denuded of epithelinm, a diphtheric membrane covering the entire cecum and colon, raised button ulcers, fungoid growths, and follicular abscesses were observed. Pneumonitis, pleuritis, and pericarditis were frequently found. Edematons and hemorrhagic lymph glands were practically constantly present. The spleen was usually small and the kidneys showed a pale cortex, frequently with hemorrhagic spots. These latter were variations from the usual description of hog cholera. Swine plague bacilli were obtained from the hogs showing lung lesions.

2. St. Johns, Mich.-Hog cholera had been prevalent in this locality for several years. From July to November two townships had lost about 1,000 head. The loss was about 60 per cent. The presence of a severe diarrhea characterized this outbreak. Autopsy on three animals showe 3 lesions similar to those seen in the Hastings outbreak. Lung and intestinal lesions were both present.

3. Chatham, Ont.-Here also the disease had existed for several seasons. During the summer severe losses had occurred. In December, at the time we visited the locality, the disease had ceased to spread. The mortality exceeded 50 per cent. On account of the severe cold weather and the Dominion quarantine laws, but two autopsies were made. Lung lesions were most marked. The Canadian inspectors spoke of intestinal and foot lesions as occurring.

4. Belle Plaine, Ia.-George W. Dunphy, D. V.S., described this outbreak as follows: "This is a very virulent form of a mixed hog cholera and swine plague, destroying more than 90 per cent of each herd in which it appears. In the first autopsies only swine plague lesions were found, but later I discovered well marked hog cholera lesions. In the first postmortems the stomach and intestines were practically normal. The lungs were completely hepatized. On section pus exuded from the bronchi and a bloody fluid from the lung tissue. The liver and spleen were normal in appearance. In the later postmortems I found extensive congestion, ecchymoses and thickening of the intestinal mucosa, also the characteristic projecting button ulcers of hog cholera. In the very acute cases there were extensive intestinal hemorrhages, and large blood clots were found among the intestinal contents."

5. Lincoln, Neb.-This outbreak occurred at the Nebraska Experiment Station. The disease was introduced by a pig purchased at the State Fair. A heavy loss occurred. Dr. Dunphy described the lesions as similar to those found in the Belle Plaine, Ia., epizootic. Both intestinal and lung lesions occurred.

6. Tekonsha, Mich.-Two hogs shipped by Dr. Dunphy to the laboratory were killed and examined. Both showed follicular abscesses in the large intestines, and hemorrhagic lymph glands. The other organs were apparently normal. These were convalescent cases. Hog cholera bacilli were not found.

7. State Insane Asylum, Pontiac, Mich.-This is the outbreak which is described in the succeeding section on "The Production of Hog Cholera in Swine by Inoculation with Bacteria-free Filtrates," q. $v$. 
Bacteriological examinations were made of a number of animals, as follows:

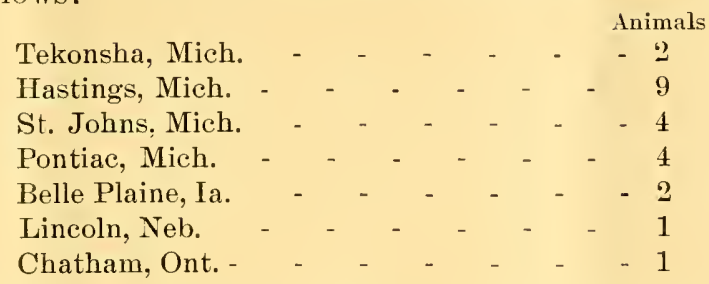

From viscera from Belle Plaine, Ia., and Lincoln, Neb., hog cholera bacilli were isolated which agreed quite closely with each other in cultural and agglutinative characters. These bacilli were but moderately virulent for experimental animals.

From the Pontiac outbreak we isolated an organism of the hog cholera group apparently identical in morphological, cultural, and agglutinative characters with the bacillus $\beta$ of swine dysentery of Theobald Smith.

In no other instance were we able to isolate true hog cholera bacilli, although a number of organisms quite closely related were found.

\section{TECHNIQUE.}

Suspensions of agar cultures 16 to 24 hours old in salt solution saturated with tri.- chlor.- tertiary- butyl-alcohol (chloretone) were employed throughout this work. Dilutions of the serum to be tested were made in physiological salt solution, and equal parts of the serum dilution and the bacterial suspension mixed in small test tubes $(8 \times 80 \mathrm{~mm}$.) The tubes were then placed in the incubator at $37^{\circ} \mathrm{C}$. They were examined first at the end of two hours and again after 16 or 20 hours. The highest dilutions in which plain floceules showed were taken as the limit. Although the bacterial suspension remained fit for use for many weeks, fresh suspensions were usually made for each test. Control tests with young broth cultures and the microscope were made from time to time. In a number of instances dried blood was used; this we found reacted fully as well as the fresh serum.

THE PRESENCE OF AGGLUTININS FOR HOG CHOLERA BACILLI IN THE BLOOD OF NORMAL HOGS.

The blood of normal hogs usually agglutinates hog cholera bacilli in fairly high dilutions. For our purpose it was necessary to determine the normal range. Of. 22 specimens of normal hog blood examined 3 agglutinated hog cholera bacilli in dilutions of 
$1-200$, 11 in dilutions of less than 100 ; the remainder between these limits. (The smaller amount of agglutinin is usually found in the blood of the younger hogs.) The blood of normal hogs agglutinates not only the liog cholera bacillus but also others: swine plague, colon and paracolon bacilli in dilutions of abont the same strength as the hog cholera organism. $\downarrow$

From a consideration of these data it was concluded that an agglutination in a dilution of less than $1-300$ is of no value in the diagnosis of an infection by hog cholera bacilli.

\section{AGGLUTINATIONS WITH THE BLOOD OF HOGS SICK WITH OR DEAD OF HOG CHOLERA.}

The blood of diseased hogs in the outbreaks studied reacted only occasionally with hog cholera bacilli in dilutions of $1-300$. The following table gives the results of the examination of the blood of 57 different hogs from the several outbreaks:

TABLE $\Upsilon$.

The Agglutination of Hog Cholera Bicrlli by The Blood of Diseased Swrne.

\begin{tabular}{|c|c|c|c|}
\hline $\begin{array}{l}\text { Source of } \\
\text { Blood }\end{array}$ & $\begin{array}{l}\text { No. Animals } \\
\text { from which } \\
\text { Blood was } \\
\text { Tested }\end{array}$ & $\begin{array}{c}\text { Reaction and } \\
\text { Dilution }\end{array}$ & $\begin{array}{c}\text { Hog Cholera } \\
\text { Bacillus } \\
\text { Isolated }\end{array}$ \\
\hline Hastings ........... & 7 & -200 & no \\
\hline St. Johns........... & 3 & -300 & no \\
\hline Takonsha........ & 2 & -250 & no \\
\hline Belle Plaine........ & & & \\
\hline Herd $1 . . . . . .$. & 7 & -300 & \\
\hline Herd 2... & 3 & -300 & \\
\hline Herd $3 . . . .$. & $\left\{\begin{array}{l}4 \\
0\end{array}\right.$ & +2000 & yes \\
\hline & 15 & $\begin{array}{r}1600 \\
+\quad 600\end{array}$ & \\
\hline Lincoln ... & $\{15$ & -300 & yes \\
\hline Pontiac... & $\int 7$ & -50 & \\
\hline & ( 1 & +800 & yes \\
\hline Chatham.......... & 1 & -300 & no \\
\hline
\end{tabular}

In those instances where a hog cholera bacillus was isolated from an ontbreak, the agglutinating power of the blood of the animals from this locality was tested against this particular bacillus. In those outbreaks from which no hog cholera bacillus

* That the presence of this relatively large quantity of agglutinin cannot be explained by the animals having had a previous attack of the disease is shown by their succumbing to hog cholera when subsequently exposed.

$\dagger$ The Pontiac bacillus was never agglutinated by normal hog blood in any of the trials made in dilutions of 1-50. 
was isolated the agglutinative power of the blood was tested upon several strains of hog cholera bacilli.

Table I shows plainly that agglutination is of no value for the diagnosis of hog cholera, as the disease is at present defined. The presence of a positive reaction, if obtained in dilutions of $1-300$ or over, does, however, indicate an infection with hog cholera bacilli.

II.

THE PRODUCTION OF AGGLUTININS FOR HOG CHOLERA BACILLI IN SWINE.

Charles T. McClintock, Charlej H. Boxmeyer and J. J. Siffer.

AGGLUTINATION AFTER VACCINATION WITH HOG CHOLERA VACCINE.

The vaccine used in these experiments was prepared by growing 11 different strains of hog cholera and one of swine plague bacilli upon agar in quart whiskey flasks. After incubating at $37^{\circ} \mathrm{C}$. for 60 hours the growth was loosened from the agar surfaces with a bent glass rod and washed off with a .75 per cent salt solution saturated with tri.- chlor.- tertiary- butyl-alcohol. The suspension was then strained through India mull to remove particles of agar and cotton, the several strains mixed, and heated to $50^{\circ} \mathrm{C}$. for 30 minutes. The vaccinations were practically always made intraperitoneally. The animal was bled seven or eight days afterwards from the tail or ear.

Most of the animals reacted promptly to the injection producing relatively large quantities of agglutinin. A series of four hogs was vaccinated with 25 c.c. of hog cholera vaccine and the agglutinating power of their blood tested each day. The amount of agglutinin in the blood began slowly to rise on the second and third day, then it rose rapidly till the sixth day when it attained its maximum. It stayed at this point for about three days. During the succeeding week it dropped either suddenly or gradually to a relatively constant level at which it remained for some time. A second vaccination 24 days after the first raised the level slightly, but it never attained its former maximum height. This is not 


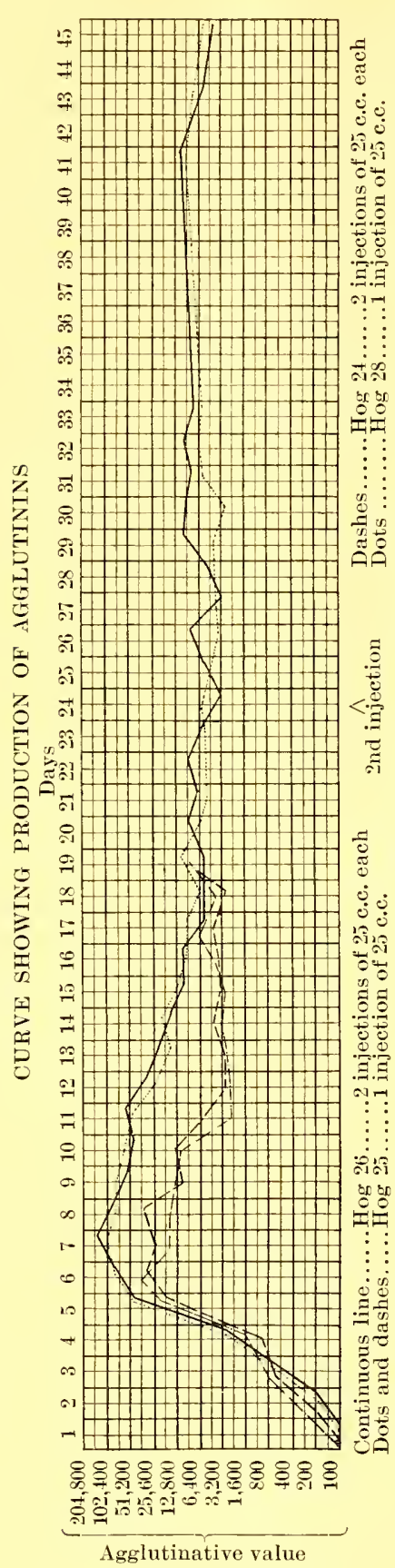

true, however, in all cases, the blood of some hogs showing the highest agglutinating power after repeated injections.

Twenty-six vaccinated hogs, bled seven days after injection, showed the following maxima:

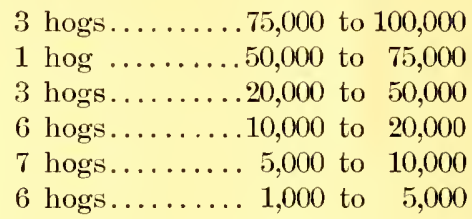

The quantity of agglutinin produced varied somewhat with the lot of the vaccine used. The size of the dose, however, appears to have had no influence upon the amount of agglutinin produced, this depending apparently upon an idiosyncrasy of the animal.

TABLE II.

RELATION OF AMOUNT OF VACCINE TO HEIGHT OF AGGLUTINATION.

\begin{tabular}{|c|c|c|c|}
\hline $\begin{array}{l}\text { No. of } \\
\text { Hogs }\end{array}$ & $\underset{\text { Vaccine }}{\text { Amount of }}$ & $\begin{array}{l}\text { Lots of } \\
\text { Vaccine }\end{array}$ & $\begin{array}{l}\text { Agglutination } \\
\text { Limit Seven } \\
\text { Days after } \\
\text { Injection }\end{array}$ \\
\hline $\begin{array}{l}1 \ldots \ldots \\
1 \ldots \ldots \\
1 \ldots \ldots \\
1 \ldots \ldots \\
1 \ldots \ldots \\
1 \ldots \ldots \\
3 \ldots \\
1 \ldots \ldots \\
1 \ldots \\
1 \ldots \\
1 \ldots \\
1 \ldots \\
1 \ldots \\
2 \ldots \\
1 \ldots \\
1 \ldots\end{array}$ & 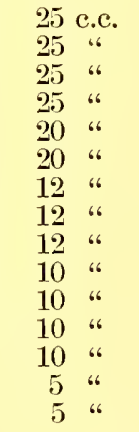 & $\begin{array}{l}.05183 \\
.05183 \\
160 \mathrm{H} \\
160 \mathrm{H} \\
.05072 \mathrm{~B} \\
.05072 \mathrm{~B} \\
160 \mathrm{H} \\
160 \mathrm{H} \\
160 \mathrm{H} \\
160 \mathrm{H} \\
160 \mathrm{H} \\
.05072 \mathrm{~B} \\
.05072 \mathrm{~B} \\
160 \mathrm{H} \\
160 \mathrm{H}\end{array}$ & $\begin{array}{r}50,000 \\
10,000 \\
5,000 \\
2,000 \\
1,200 \\
300 \\
10,000 \\
20,000 \\
7,500 \\
15,000 \\
5,000 \\
1,000 \\
300 \\
10,000 \\
5,000\end{array}$ \\
\hline
\end{tabular}


In a few cases agglutinins had not appeared in the blood seven days after vaccination.

Hogs inoculated with mixed hog cholera and swine plague vaccine show in their blood an agglutinin for the swine plague as well as the hog cholera bacillus.

Two hogs with an agglutinating limit before treatment of 50 and 75 for swine plague bacilli and 100 and 150 respectively for hog cholera bacilli, showed seven days after vaccination with mixed vaccine an agglutination of $1-500$ and $1-10,000$ for swine plague, and 1-15,000 and 1-50,000 for hog cholera bacilli.

AGGLUTINATING POWER OF THE BLOOD AFTER INOCULATION WITH LIVE HOG CHOLERA BACILLI.

Hog No. 103, weighing 75 pounds, received into the ear vein six c.c. of an 18-hour culture of a hog cholera bacillus obtained from the Lincoln (Nebraska) outbreak, but a few weeks after its isolation. The animal was bled to death on the 13th day. The following curve shows the agglutinating action of its serum upon various strains of hog cholera bacilli:

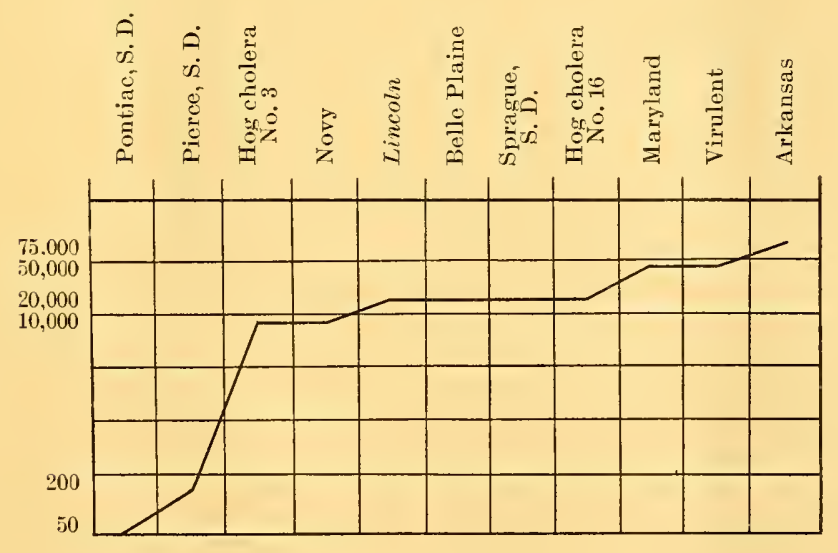

A hog injected subcutaneously with five c.c. of the Pontiac bacillus agglutinated seven weeks afterward the injected bacillus in a clilution of $1-800$, but did not agglutinate the Arkansas bacillus in a dilution of $1-50$. 
The following curve of agglutination by the serum of a rabbit inoculated with the Pontiac organism shows graphically the agglutination relations of the hog cholera and swine dysentery bacilli:

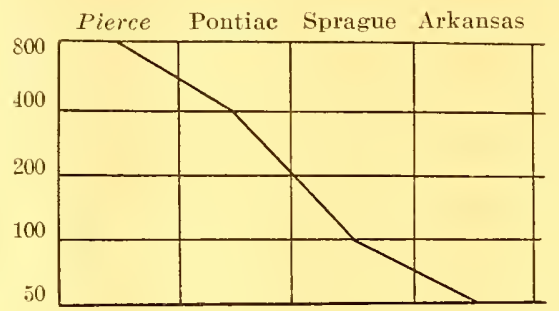

\section{MAY HOG CHOLERA BACILLI BE PRESENT IN THE ORGANISH AND THE AGGLUTINATION REACTION REMAIN NEGATIVE?}

Case 1.- Hog. No. 106 was fed viscera of hogs in which the Arkansas hog cholera bacillus was present. He died seven days afterward. From the spleen, liver, and mesenteric glands pure cultures of the same hog cholera bacillus were obtained. The blood serum of this animal gave no reaction either with the bacillus isolated or with the original culture. This observation was confirmed by a repetition of the test.

Case 2.- Hog No. 105 received intravenously six c.c. of the juice of the organs of hog 48, filtered through paper. He was dead on the 13 th day. Autopsy showed typical swine plague lesions. Cultures from the various organs gave a mixture of the swine plague and hog cholera bacillus.*

The blood serum gave no agglutination in dilutions of 1-300 with the hog cholera bacillus isolated.

The blood serum of two hogs from the Pontiac ontbreak, from which hog cholera bacilli were isolated, gave no agglutination either with the Pontiac organism or strains of ordinary hog cholera bacilli in dilutions of 1 to 50 .

* The Arkansas bacillus, which was kindly sent us by Dr. Theobald Smith, is admirably adapted for experimental work on account of the readiness with which it may be identified. It differs markedly in the appearance of its colonies from all other strains we have studied. On broth it forms a thin, white, brittle membrane. On agar it forms characteristic dry, slightly wrinkled colonies, readily detached in one piece from the agar surface. It is difficult to break up the growth and make up a homogeneous suspension. Its action upon various culture media and toward agglutinating serum was almost identieal with that of the other strains in our possession. The peculiarities were retained through repeated animal passages. 
SUMMARY.

1. The serum of normal hogs agglutinates strains of ordinary hog cholera bacilli in dilutions occasionally as high as 1 to 250 . For this reason we consider a reaction in a dilution of less than 1 to 300 without diagnostic value.

2. The bacillus of swine dysentery is not agglutinated by normal blood in such high dilutions.

3. Agglutination is of no value for the diagnosis of hog cholera, as the disease is at present defined.

4. The presence of a positive reaction does, however, indicate an infection with hog cholera bacilli.

5. There are occasional instances of both natural and artificial infection in which no increase of the agghtinins for hog cholera over those normally present can be demonstrated.

6. The maximum amount of agglutinin develops in a hog's blood within six or seven days after a single inoculation with hog cholera vaccine.

7. Hogs react to intraperitoneal injections of hog cholera vaccines, usually with the production of large quantities of agglutinins, the amount of the vaccine bearing no relation to the amount of agglutinin produced.

III.

THE PRODUCTION OF HOG CHOLERA IN SWINE BY INOCULATION WITH BACTERIA-FREE FILTRATES.

Charles H. Boxmeyer.

Repeated failures, after thorough and prolonged search, to isolate hog cholera bacilli from the carcasses of hogs which had succumbed to the disease in certain Michigan outbreaks, the failure of the blood serum of any of these animals to agglutinate any of several hog cholera strains, together with the inability to produce the characteristic lesions of hog cholera by the feeding or injection of hog cholera bacilli, led to a search for some other agent as the etiological factor of these outbreaks.

Opportunely, the Burean of Animal Industry' at this time

I DeSchweInetz and Dorset, Bureau of Animal Industry, 1503, Circular 41. 
published a preliminary report upon "A Form of Hog Cholera Not Caused by the Hog Cholera Bacilins," in which they stated that they were able to transmit the disease to healthy animals "by the subcutaneous inoculation of certain body fluids, these fluids being always proved by careful bacteriological examination, by filtration through the finest porcelain filters, and by the inoculation of guinea pigs and rabbits, to be free from hog cholera and swine plagne bacilli."

Experiments were immediately begun along this line, as the confirmation of this work wonld explain the failure of all attempts to immunize hogs by means of vaccines or sera against hog cholera, and point out the way to a possibly successful method of combating this disease.

\section{EXPERIMENTS WITH FILTERED BODY FLUIDS.}

The infections material employed was derived from an epizootic of hog cholera that occurred at the State Insane Asylum at Pontiac, Michigan, in May, 1904. At the time of investigation the disease had been current for about six weeks. The herd had originally contained 90 head-Berkshires, Chester-whites, and crosses - weighing from 100 to 200 pounds. Fifty deaths had occurred, and practically all the remaining hogs showed evidence of a more or less advanced stage of the disease. The symptoms shown were fever, reddening of the ears and skin covering under surface of the body, partial paralysis of the posterior extremities, and eyelids swollen and glued together. Some animals exhibited a marked constipation, while others showed a severe diarrhea. The superintendent kindly permitted us to kill two of the sickest animals for postmortem examination. Autopsy showed the following :

Hog No. 1.- Chester-white, male, weight 100 pounds. Had shown disease symptoms for about one month. Condition fair. Weakness of the hind legs. Killed and examined. Skin shows slight flush. Inguinal glands not enlarged. Spleen hyperplastic. Liver pale, of a yellowish color. Kidneys with pale cortex dotted with minute petechiæe. Mesenteric glands edematous and hemorrhagic. Cecum and colon filled with hard, impacted feces. Mncosa dark colored. Two indurated ulcers about $15 \mathrm{~m} . \mathrm{m}$. in diameter at the base of the ileocecal valve. Echinorhynchi and ascarides present. Small intestines little changed. Apices of both lungs hepatized, with pleural adhesions at these points. Visceral pericardium petechiated. 
Hog No. 2.- Berkshire, weight 125 pounds. Marked weakness in both hind and fore legs. Condition fair. Killed and examined. Inguinal lymph glands not enlarged. Spleen slightly enlarged and covered with fleshy villi. Kidneys with pale cortex sparsely petechiated. Liver pale. Intestinal mucosa shows no marked change, and intestines are filled with a large quantity of semi-fluid feces. Lungs show fairly large sub-pleural ecchymoses. The posterior lobe of reft lung is congested and shows beginning of hepatization. Lymph glands swollen and slightly hemorrhagic.

Cultures from the various viscera gave a variety of organisms, from which we were able to isolate a hog cholera-like bacillus, identical in morphological, cultural, and agglutinating characters with the bacillus of swine dysentery $\beta$ of Theobald Smith. One-half c.c. of a 24-hour culture of this bacillus injected subeutaneously into a rabbit produced death in six days. Postmortem showed the focal necroses of the liver characteristic of an infection by members of the hog cholera group. The blood serum of this rabbit agglutinated the injected bacillus and the swine dysentery bacillus $\beta$ of Smith in a dilution of $1-800$, but produced no agglutination in dilutions of 1-50 with the ordinary strains of hog cholera bacilli. Five c.c. of a 16-hour broth culture of this bacillus in the fourth generation, and four days after isolation, produced no other effect than a considerable local abscess when injected subcutaneously into a 20 -pound hog during the 30 days he was under observation. The animal gained rapidly in weight during this period.

Portions of the spleen and liver of the above hogs were brought to the laboratory and fed to hog No. 114, a Chester-white pig, weighing 20 pounds. He was chloroformed on the 29th day after infection, being moribund. The blood was collected aseptically from the carotid artery.

Postmortem: Great emaciation. Ears and snout blackened and necrotic. Feces thin, yellow, fluid. Inguinal glands enlarged, not hemorrhagic. Spleen hyperplastic and bound to the cecum by dense adhesions. Liver yellowish. Kidneys pale, with a few minute petechiæ. Mesenteric and gastric glands enlarged and hemorrhagic. Small intestines little changed. Colon and cecum show hemorrhagic areas on their serous surface. Mucosa thickened and covered throughout with a diphtheritic layer yellowish in places, black in others. Button ulcers show above this membrane. Lungs slightly congested. Tracheal glands hemorrhagic. Pure cultures of bacillus pyocyaneus were obtained from the spleen, liver, kidney, and mesenteric glands.

\section{SECOND PASSAGE. FIRST FILTRATE.}

The blood of this hor (No. 114) was mixed with two parts of sterile physiological salt solution and filtered through a large 'Berkefe!d filter (Laboratory Cylinder No. 2), using suction. The filtrate was removed from the sterile suction flask by means of a sterile pipette, filled into a sterile syringe, sealed, immersed in five per cent carbolic acid solution, and wrapped in cotton moistened with the same disinfectant. So wrapped, the syringe was handed to a second person, who had never been near the diseased hogs, nor in the room where the filtration took place. This person made the injection. The animal chosen was a Chester-white pig, No. 117, weighing 25 pounds. It eceived (June 17) intraperitoneally 10 c.c. of the above filtrate, equivalent to 
3.3 c.c. of undilnted serum. The animal was placed in an isolated pen at a distance from the diseased hogs. The stableman who attended him never came in contact with diseased hogs nor their attendant. The same attendant cared for some uninoculated hogs during this time, which remained well during the experiment, but later succumbed to the disease after a normal incubation period when exposed to infection. The animal remained active, but lost weight, and became much emaciated. A few days before death, he showed discolored skin, tottering gait, and blood-stained urine. He died during the night of July 11. 24 days after inoculation.

Postmortem: Body emaciated. Skin discolored and scabby. Inguinal and cervical lymph-glands swollen and intensely hemorrhagic. Numerous small subcutaneous hemorrhages. Peritoneal cavity contains considerable bloody serous exudate, in which are particles of fibrin. The bladder has the appearance of a large blood-clot; the walls are greatly thickened and infiltrated with blood. Both large and small intestines show numerous hemorrhagic spots on the serous surface. The mucosa of colon and cecum show numerous large yellowish button ulcers with black centers. These ulcers are occasionally confluent. The lungs show numerous petechice and a nodule of walnut size. Heart pale and flabby. Visceral pericardium dotted with many small ecchymotic spots.

Portions of the filtrate with which the above hog was injected were tested, as follows:

Five c.c. was added to 500 c.c. of broth.

Two c.c. was added to 500 c.c. of broth covered with oil.

The first flask showed, after some days, a slight cloudiness. Subcultures and injection of 2.5 c.c. of the flask contents subcutaneously into a rabbit failed to show any bacteria. Microscopic examination showed numerous minute granules adhering together in clumps. These were difficult to stain with the ordinary anilin dyes, and probably were precipitated albuminous substances. effect.

A guinea pig (300 grams) received seven c.c. subcutaneously without

A mouse (20 grams weight) received two c.c. subcutaneously. No effect.

Rabbit No. 117, five c.c. subcutaneously, without effect.

Rabbit No. 116, five c.c. intravenously. Died on the 39th day from pneumonia. The animal showed signs of snuffles before death. Bipolar staining bacilli were found in large numbers in the pus from pleural exudate.

\section{THIRD PASSAGE, SECOND FILTRATE.}

The blood and peritoneal fluid of hog No. 117 were left in the refrigerator for 11 days, then diluted with three parts of sterile salt solution, filtered first through paper, then passed twice through a large Berkefeld filter and finally through a Chamberland Pasteur F filter using suction. 'This filtrate was filled into a syringe, sealed and handled under the same precautions as the first filtrate. Cultures on agar and broth gave no signs of growth. Rabbit No. 121 received subentaneously nine c.c. of this filtrate without result. Rabbit No. 120 , tive c.c. intravenously without effect. 
Mouse No. 150, (15 grams) one c.e. subcutaneously. Found dead on the seeond day. No bacilli could be found at the point of inoculation upon mieroseopic examination.

Hog No. 124, Chester-white, weighing 20 pounds, reeeived subcutaneously 20 c.c. (equal to five c.c. serum) of the filtrate from hog No. 117. This animal was kept in a dog-cage in an animal room at a distance from the diseased hogs, and neither the person who injeeted the animal nor the attendant ever eame in eontact with any diseased swine, nor into the room where infeetious material was handled. No one that had handled infected material entered the room during the period of isolation. The animal showed on the 11th day distinct signs of disease, reddening of the skin, loss of appetite, and intense thirst. On the 10th day a marked diarrhea set in and the pig lay erouched in the corner of the cage from which it refused to move. On the 17th day after inoeulation, the animal, being apparently moribund, was chloroformed and bled from the carotid artery, the blood being eollected aseptieally.

Postmortem: Much emaeiated. Skin disc lored. Ears purplish. Inguinal glands greatly swo!len with some hemorrhagie lobules. Spleen normal, liver normal. Cortex of kidneys pale with a few petechiae. Mesenterie and retroperitoneal glands swollen and s'ightly hemorrhagie. Pancreas normal. Colic and ceeal mueosa free from uleers, but dotted with exceedingly numerous minute hemorrhages. Lungs with small sub-pleural hemorrhages. Posttracheal glands hemorrhagic and edematous. Blood smears show a eonsiderable number of nucleated red corpuseles.

Cultures were made from the spleen, liver, kidneys and lymph glands. Broth tubes from the first two showed a few large cocei. The others were sterile.

The blood serum of this animal failed to agglutinate in 20 hours either the Pontiac swine dysentery or a typical hog cholera bacillus, in dilutions of 1-100. Cultures and inoculations of rabbits made with the blood serum of this hog showed no baeteria.

\section{FOURTH PASSAGE. UNFILTERED SERUM.}

Since the first two passages and filtrations should have eliminated all filterable organisms, and as the severity of the lesions was apparently deereas. ing it was decided to return to unfiltered serum in hopes that the more charaeteristie lesions of the disease would reappear.

Hog No. 134, Berkshire, weight 20 pounds. Reeeived subcutaneously five c.e. of the unfiltered sterile serum of hog No. 124. The same preeautions in regard to the syringe and the isolation of the animal were observed as before. On August 26, the 13th day after inoculation plain signs of the disease were present. The animal died September 6,24 days after inoculation.

Postmortem: Slight loss of flesh. Redness of skin of abdomen and chest. Inguinal lymph glands enlarged and hemorrhagic. Considerable quantity of fluid exuclate in the peritoneal cavity. Intense fibrinous peritonitis, thick layers of fibrinous exudate matting together the viseera and eovering liver and spleen. The whole length of small intestines hemorrhagic, mueosa hyperemic. Cecum and adjoining portions of colon show numerous round 
depressed ulcers from three to eight mm. in diameter. A circular ulcerated ring around the ileocecal valve. The remaining portion of the large intestines shows seattered hemorrhagic areas. Spleen slightly enlarged. Liver and kidneys apparently normal. Fibrinous pleuritis and pericarditis. Parietal pericardium adherent to the heart. Small congested and edematous areas in the apices of the lungs, other portions normal. Posttracheal glands enlarged and hemorrhagic.

Cultures made from liver, spleen and kidneys all showed growth. None of the organisms obtained were agglutinated either by a hog cholera or a swine dysentery serum.

In addition to the above series a small white hog No. 116, weight 20 pounds, was inoculated with a filtrate made by steeping the viscera brought from Pontiac in salt solution, passing through paper and a Berkefeld filter. The first two weeks he apparently gained in weight, but later appeared dull, sniffled and lay in the corner of the cage. He died on the 35th day after inoculation. The precautions against accidental infection were the same as observed before.

Postmortem: Reddening of the ears. Inguinal glands greatly enlarged with minute punctiform hemorrhages. Cervical lymph glands enlarged and hemorrhagic. Spleen dark, not enlarged. Liver normal. Small fibrinous particles adhered to the spleen and serus covering of the intestines. Mesenteric glands enlarged. Gastric and mesocolic glands bemorrhagic. Small intestines filled with yellow fluid feces. Kidneys pale with a few hemorrhagic spots. Large intestines practically normal except at the base of the ileocecal valve where were found two small yellowish ulcers. Apices of both lungs hepatized. Post-tracheal lymph glands edematous and hemorrhagic. Considerable blood-stained purulent exudate. The Pontiac bacillus was isolated from the mesenteric glands of this hog.

Early in the winter some preliminary experiments had been made with infectious material from the ontbreak that occurred at Hastings, Michigan, in September, 1903.**

Neither in material from this epizootic brought from the field nor in the animals infected in the laboratory could hog cholera bacilli ever be isolated, nor did the blood serum of any of these animals exhibit any agglutinating power for hog cholera bacilli, in excess of that normally present.

The liver and spleen of hog No. 47 (an acute hemorrhagic case produced by feeding viscera brought from Hastings) were steeped in salt solution and the fluid filtered first through paper, then through a No. 6 Berkefeld filter.

* This epizootic was complicated in one herd by foot lesions from which an anërobic bacillus, a nember of the malignant edema group, was isolated. The disease resembled blackleg in being usually confined to one-quarter of the body. The lesions consisted of a hemorrhagic edema with emphysema extending along the limb into the foot. Ulcers were present on the foot and between the toes. In one animal the entire liver was emphysematous, and had the appearance and feel of lung tissue. A rabbit inoculated with edema fluid from this animal showed a similar condition of the liver. These lesions were reproduced in the laboratory in hogs fed infected carcasses. The bacillus died out before it could be more carefully studied. 
Hog No. 62, a Chester-white, weighing 30 pounds, received intraperitoneally four c.c. of the above filtrate. No bacteria were detectable in this filtrate by cultures or animal inoculation. Fifteen days after inoculation, the pig showed diarrhea and blood-stained feces. Plates (Drigalski \& Conradi) made from the feces failed to reveal hog cholera bacilli. Death occurred in 38 days. Autopsy showed discoloration of the skin, hemorrhagic lymph glands, small dark spleen, ecchymotic mucous and serous membranes, and the colon and cecum had scattered thickly throughout their length small yellowish nodules about the size of a goose shot. These nodules were due to the distention of Klein's glands by cheesy pus. Cultures showed a variety of bacilli but no hog cholera bacilli could be isolated.

Hog No. 58, Chester-white, 30 pounds, received intraperitoneally two c.c. of the edema fluid of hog No. 47, filtered through a small Berkefeld filter. Cultures and animal inoculations of the filtrate showed no bacilli. The course of the disease was similar to that of hog No. 62. The animal died on the 38:h day after inoculation. The pathological appearances were similar to those in hog No. 62. The colon and cecum showed numerous raised button ulcers 6 to $20 \mathrm{~mm}$. in diameter scattered along their length, and a large necrotic patch at the ileocecal valve.

Hogs No. 109 and No. 110, weighing 25 pounds each, received subcutaneously respectively 14 c.c. of a Berkefeld No. 2 and 10 c.c. of a Pasteur F. filtrate of an emulsion of the viscera of hog No. 106 (infected with material from hog No, 47). Hog No. 109 died on the 20 th and hog No. 110 on the 24th day a'ter infection. No characteristic lesions were present. Both showed slight pneumonia and hyperemia of the intestinal mucosa. Cultures from hog No. 110 gave no growth. Hog No. 109 gave pure cultures of streptococei. The blood of neither hog agglutinated hog choler bacilli in dilutions of $1-300$.

In summarizing the data we find that of five hogs inocnlated with sterile Berkefeld filtrates derived from two distinct outbreaks, all died within a period varying from 19 to 38 days, a period which coincides with that observed in cases of natural infections and those produced by feeding infected material. Four of these (Nos. 62, 58, 114, and 116) showed the characteristic intestinal ulcers of hog cholera. Both hogs (Nos. 110 and 12t) inoculated with Pasteur filtrates died, one on the 24 th, the other on the 19th day after inoculation. Though the source of the infecting filtrate was different (one Hastings, the other Pontiac), both showed similar lesions, which, while not characteristic of hog cholera are frequently found in natural infections. The blood serum of one of these (hog 12t), when injected into another hog (No. 134), produced the characteristic lesions of hog cholera, the animal dying in the usual period, namely, 24 days. 
The above observations are in agreement, on the whole, with those of the Bureau of Animal Industry, but differ in that we had to deal with the chronic form of the disease, while their virus always gave rise to the acute. In an attempt to produce an acute infection a 100 -pound $\operatorname{hog}$ received an injection of five c.c. of virulent blood serum into the ear vein. He showed on the eighth day a sharp rise of temperature and refused food. On the 14 th day he had diarrhea and other symptoms of the disease, but was still strong and death would probably not have occurred for a couple of weeks. As virulent blood was required for immunizing experiments, this animal was bled to death on the 15 th day after inoculation. This experiment may be considered a failure so far as the production of an acute form of hog cholera is concerned. The same procedure applied to smaller hogs would probably have been successful. as they are much more susceptible to infection.

The failure to isolate from the Hastings ontbreak a hog cholera bacillus, although a number of animals were examined and the infection passed from animal to animal for several generations in the laboratory, the ease with which hog cholera bacilli can be recovered when once introduced into the system, the difficulty of infecting swine with any but large quantities of the most virulent bacilli, the readiness with which the disease is naturally spread, taken together with the results from the above filtration experiments seem to show conclusively that the hog cholera bacillus is not the primary factor in the production of hog cholera, if the disease studied were such.

Yet let us assume that the hog cholera bacillus produces in the blood of the infected animals a toxin, and that none of the toxin is used up in producing the disease. In its serial passage through hogs No. 117 and No. 124, calculating the blood as five per cent of the body weight, we would have diluted the original toxin 20,000 times. The third $\log$ received five c.c. of this dilution or .00025 c.c. of the original, which is equivalent to .000000025 c.c. per gram weight of hog - a toxin whose potency has never been equalled except possibly in the case of purified tetanus toxin. $\mathrm{U}_{\mathrm{p}}$ to the present no substance of any great toxic 
power has been obtained from bacilli of the hog cholera typhoid group, and toxins of the diphtheria tetanus type are wholly unknown among its members. In the present state of our knowledge, it seems unreasonable to suppose that a toxin of so great a potency is formed. The following experiment furnishes additional evidence that the disease-producing agent is not an unorganized toxin. Hog No. 125, weighing 20 pounds, received five.c.c. of chloretone-saturated blood of hog No. 115. During the 20 days he was under observation he showed no signs of disease, and, when exposed later with an infected animal, died showing the typical lesions of hog cholera. Two-thirds of a cubic centimeter of the same blood without the addition of chloretone produced typical hog cholera when injected subcutaneously into hogs of the same size. Tri.- chlor.- tertiary- butyl-alcohol has been shown in this laboratory to be without effect upon diphtheria and tetanus toxins, but rapidly destructive to non-spore-bearing organisms. This experiment, in connection with the preceding, would seem to show that the infecting agent was some organism readily killed by mildly germicidal substances, and capable of passing through the pores of Berkefeld and Chamberland filters.

The above facts appear to place hog cholera in the group of diseases among which are rinderpest, peripneumonia, ${ }^{1}$ and foot and mouth disease, ${ }^{2}$ all of which are capable of being transmitted by a filterable virus. With the exception of peripneumonia, the causative organism of none of these has ever been cultivated or seen under the microscope. The size of the organism of peripneumonia which has been cultivated by Nocard and Roux lies at the limit of microscopic vision. The pathological lesions found in hog cholera are quite similar to those described for rinderpest, as seen in the Philippines, ${ }^{3}$ and the disease is probably more closely related to this than to any of the others.

The virus differs from that of rinderpest, however, in the greater readiness with which it passes through filters ${ }^{4}$ and its

1 NocARD, Handbuch d. Path. Nicroorganismen, 1903, 3, p. 682.

2 LöfFler, Centralbt. f. Bakt., 1898, 23, Abth. 1, p. 371.

3 Joblixg, Report of the Philippine Government Laboratories, 1903, p. 363.

4 NiColle and ADIL-Bex, Ann. de l'Inst. Pasteur, 1902, 16, p. 56. 
greater resistance to physical and chemical agents. Koch ${ }^{1}$ states that the virus of rinderpest dried at $31^{\circ} \mathrm{C}$. was inert; also that the addition of 10 per cent glycerin to virulent blood destroyed its infectious qualities.

I have found that the blood serum of diseased hogs dried at $37^{\circ} \mathrm{C}$. or the serum to which one-third its bulk of glycerin had been addert did not suffer in virulence. When tested one month after preparation, it caused apparently as severe a form of disease as the fresh serum.

IV.

\section{IMMUNIZATION AGAINST HOG CHOLERA.}

Charles H. Boxmeyer and Charles T. McClintock.

When preliminary experiments had shown that hog cholera could be transmitted by a filterable virns, the method employed by Kolle and Turner ${ }^{2}$ in combating rinderpest at Kimberly, South Africa, snggested itself as applicable in this disease also. This methor consisted in the simultaneous injection of virulent blood and the blood serum of an immune animal. The source of the immune blood was at first cattle that had recovered from the disease either naturally contracted or produced by inoculation with the blood of diseased animals. Later the serum of animals, subsequently hyper-immunized by the injection of large quantities of virulent blood, was used with still better success. Roger's ${ }^{3}$ modification, the injection of a second somewhat increased quantity of infectious blood after the disappearance of the reaction from the first injection of virulent and immune blood, also seemed worthy of trial. In addition, attempts were made to immunize hogs by the injection of diseased blood dried at a temperature of $37^{\circ} \mathrm{C}$. and blood to which one-third of its weight of glycerin was added.

EXPERIMENT WITH DRIED BLOOD.

Hog 120, Chester-white female, 20 pounds, received subcutaneously, dissolved in normal salt solution, 0.1 gram of diseased blood which had been

1 Deut. med. Wchnschr., 1897, 23, pp. 225-41. 2 Deut. med. Wchnschr., 1897, pp, 793, 818

3 Zeitschr. f. Hyg. u. Infectionsk., 1900, 35, p. 59. 
dried at $37^{\circ} \mathrm{C}$. for 36 hours, 14 days previously. On the third day the animal showed loss of appetite with an inclination to remain in its litter. On the fifth day it refused food. The skin showed a bright flush, and a marked diarrhea was present. There was but a slight rise in temperature (see temperature curve). The animal gradually grew worse and died on the 29 th day after inoculation. Autopsy showed typical hog cholera lesions, the colon and cecum containing numerous ulcers both of the deep and button type scattered along their length.

HOG 1_0

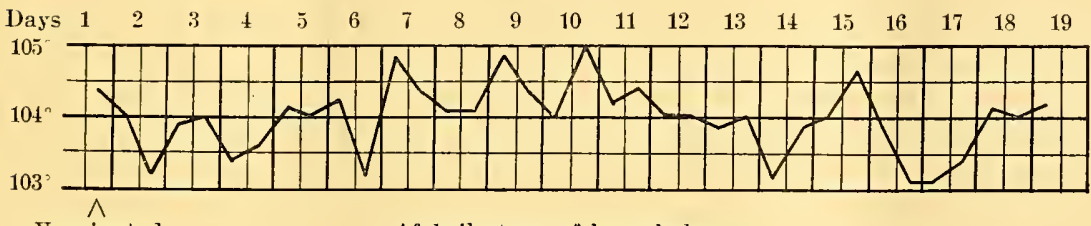

Vaccinated

Afebrile type of hog cholera.

\section{EXPERIMENTS WITH GLYCERINATED BLOOD.}

I. Hog 121, male Chester-white, weighing 20 pounds, received subcutaneously one c.c. of freshly prepared glycerinated blood (blood two parts, glycerin one part). On the third day it showed loss of appetite and languor. On the fifth day refused food and was constipated. On the seventh day the temperature had risen to $105 \mathrm{~F}$., and attained a maximum of $107^{\circ} \mathrm{F}$. on the $12 \mathrm{th}$ day. The animal being moribund was chloroformed on the 20th day. Autopsy showed typical lesions, colon and cecum being covered with numerous depressed circular ulcers. The rectal mucosa was also badly ulcerated.

HOG 121

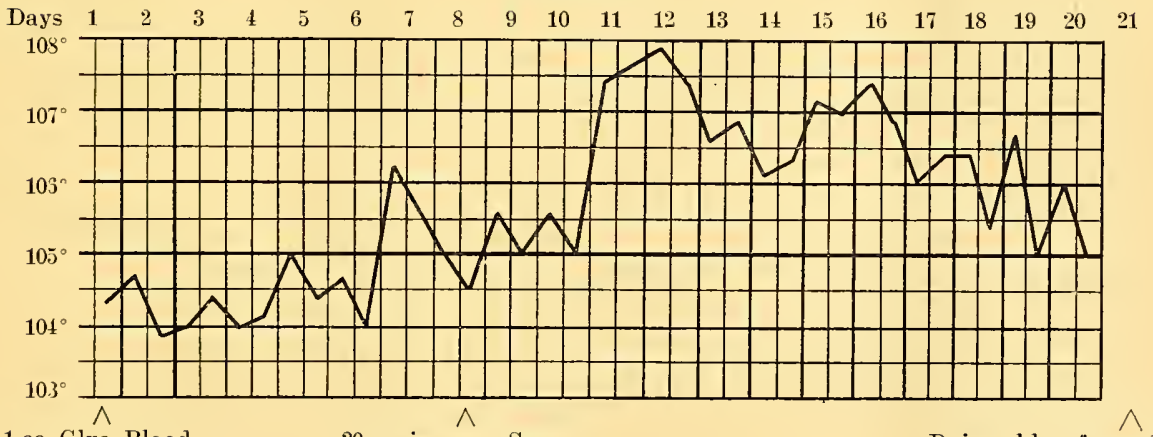

1 cc. Glyc. Blood

20 cc. immune Serum

Dying chloroformed

Febrile type of hog cholera.

II. Hog 129, Chester-white female, weighing 40 pounds, received one c.c. of same glycerinated blood now 24 days old. It showed loss of appetite on the third day, but still fed a little. On the 15th day the temperature rose suddenly, animal showed reddening of the skin, refused to eat and appeared very ill. Death occurred on the 31st day after injection. Autopsy showed typical hog cholera lesions. 
These experiments showed no attenuation of the virus.

Hog 125 received five c.c. of the same diseased blood saturated with chloretone. During the 20 days it was under observation, the animal showed no signs of disease, and, when exposed with a diseased hog, contracted the disease after the regular incubation period, and died on the $22 \mathrm{~d}$ day after exposure, showing numerous ulcers in the colon and cecum. In this instance the chloretone had apparently destroyed the infecting agent and the injection produced no immunity.

\section{EXPERIMENTS WITH SIMULTANEOUS INJECTION OF VIRULENT AND} IMMUNE BLOOD.

Two hogs furnished the immune serum employed. One of these, hog No. 113 , was repeatedly fed infected viscera. These failed to produce any noticeable disease. The animal was subsequently further immunized by the injec tion of considerable quantities of filtrates. He was chloroformed and bled from the carotid. Postmortem showed no marked lesions. The colon and cecum were free from ulcers or scars.

The second hog, No. 108,* was also fed infected viscera without effect and later confined with a diseased animal, from which he contracted the disease which failed to prove fatal, but left him badly stunted. He was further immunized by the feeding and injection of large quantities of infectious material which in no instance produced any further reaction. He was chloroformed and bled from the carotid.

In both cases the blood serum was preserved by the addition of four parts per 1000 of trikresol.

Hog No. 118, Chester-white, weight 30 pounds, received subcutaneously, on one side, one c.c. of diseased blood, and on the other side, five c.c. of immune blood. The animal showed a rise in temperature on the fourth day with loss of appetite and symptoms of hog cholera. The temperature attained its maximum on the sixth day, and fell to normal on the seventh, where it remained till the 11th day, on which a relapse set in, and the animal died on the 34 th day.

HOG 118.

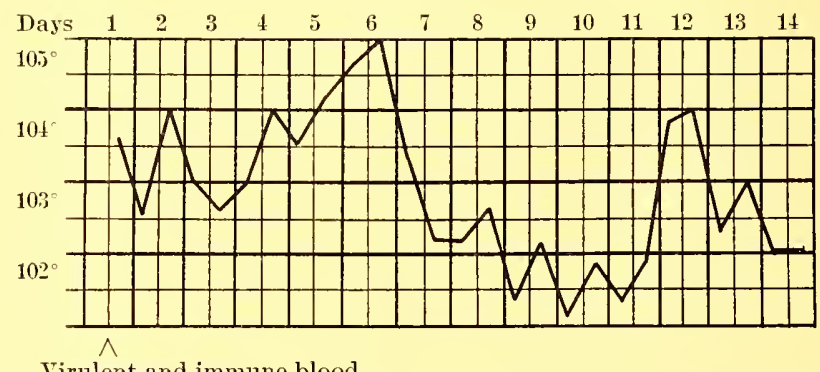

Virulent and immune blood

* This hog was fed large quantities of the viscera of two hogs that had been killed by intravenous injection of the Arkansas $\log$ cholera bacillus. He failed to show any effeets from this feeding though under observation six weeks. Later he was fed viscera from bogs naturally infeeted. These, however, had been kept for some months in the refrigerator, and had probably largely lost their infeetious qualities. 
Compare with the following :

HOG 119. .

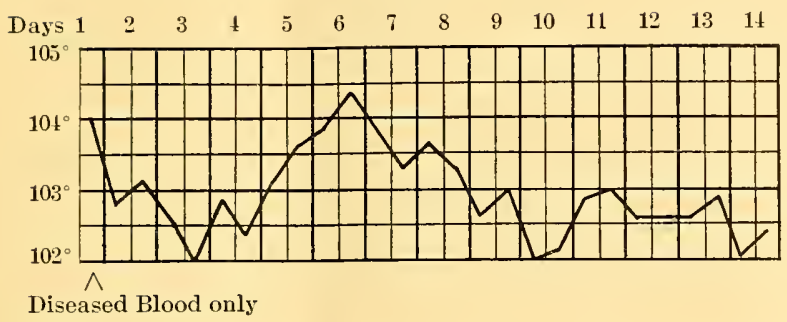

Hogs Nos. 126, 127 and 131, each weighing 20 pounds, received in the same manner as the preceding one c.c. each of diseased blood (No. 126 dried, No. 127 and No. 131 glycerinated blood) and 10 c.c. of immune blood. All showed loss of appetite and slight rise of temperature on the fourth day. The temperature attained its maximum, 106 to $107^{\circ} \mathrm{F}$., on the seventh or eighth day, and in the case of 126 and 127 it returned to normal on the 11th day, and showed no further rise. In the case of No. 131 the temperature remained high until the 13 th day, after which it dropped and remained normal.

On the 16th day hogs No. 126 and No. 127 were confined with a diseased hog. On the sixth day after exposure their temperature rose suddenly and a mild form of hog cholera set in. Both animals recorered; No. 127 without showing any appreciable loss of weight. In the case of No. 126, however, the disease continued longer and left the animal somewhat emaciated.

Hog No. 131, although constantly exposed with diseased animals has shown no further rise in temperature or signs of the disease.

Hog No. 130, black male, weighing 10 pounds, received subcutaneously one c.c. of glycerinated diseased blood and 10 c.c. of immune blood. It was noticed at the time of injection that the hog had a slight cough, some difficulty in breathing, and that there was a purulent discharge from the nose. He appeared quite sick on the sixth day, gradually grew worse, and died on the 18th day after inoculation. Autopsy showed typical hog cholera lesions. In addition the lungs were almost completely hepatized. This was apparently a case of latent swine plague complicating the vaccination and precipitating the fatal result.

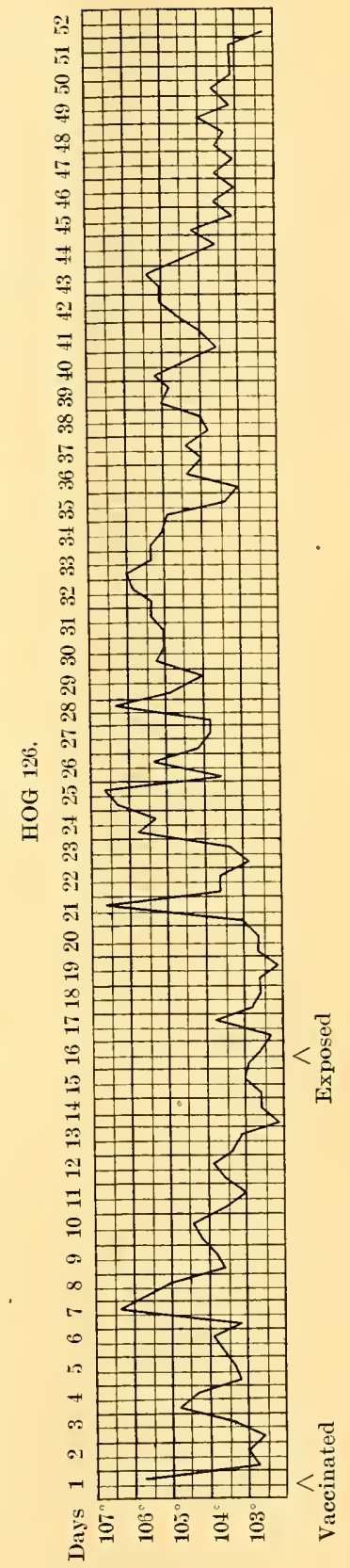


Hogs No. 122 and 123, Chester-white sows, weighing 200 pounds each, (sow No. 122 was pregnant). Each received 20 c.c. of immune serum subcutaneously. Two days afterwards 1.5 c.c. of glycerinated blood. Five days afterward both showed loss of appetite, slight reddening of the skin and indispo-

HOG 127.

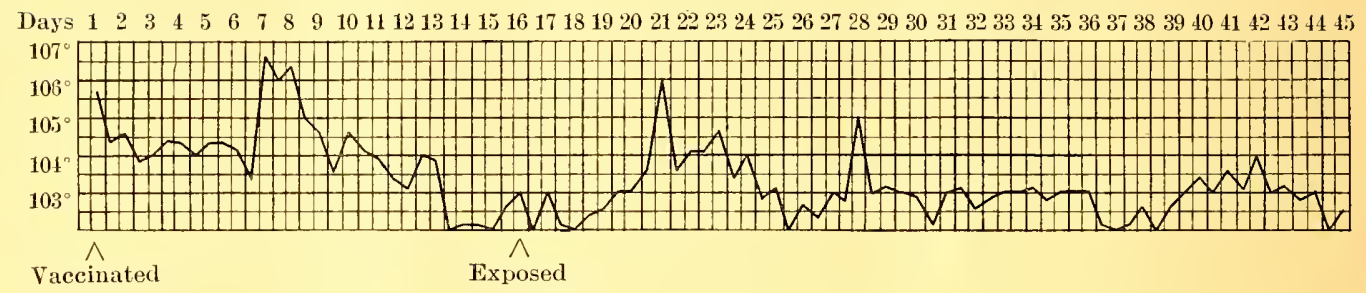

sition. On the 10th day they fed normally again. Twenty-one days after inoculation each received five c.c. of virulent blood. Having shown no effect from this injection 28 days afterward they received 100 c.c. of virulent blood and three and eight days later a second and third injection of 100 c.c. each, from which no effect other than a slight local reaction was observed. No. 122 gave birth at term to a litter of healthy pigs.

Hogs No. 132 and No. 133, Chester-whites, weighing 100 pounds, received each, subcutaneously, 1.5 c.c. of glycerinated blood and 10 c.c. of immune serum. They became sick on the 12th and 14th day, refusing to eat and showing indisposition and a considerable rise of temperature. On the 20th day the temperature fell to normal, their appetite improved and they appeared on the 29th day, perfectly healthy. They and the sows Nos. 122 and 123 were exposed to infection from hogs in a neighboring pen during this entire period.

The results from this simultaneous method of immunization are on the whole satisfactory. The larger animals have shown themselves readily immunized against the disease, the process of immunization prodncing no marked illness, no considerable loss of weight, nor tendency to stunt the growth, items of the greatest importance in the practical application of any method. Younger hogs react much more strongly to the vacination, still we have been successful in immunizing them also. The failures can be laid in the case of No. 118 to the administration of an insufficient amount of immune serum, and in the case of No. 130 to the presence of latent swine plague.

The second rise in temperature in hogs Nos. 126 and 127 may possibly be a relapse, but more likely a re-infection, the reaction from the vaccination being in both cases extremely mild and probably insufficient to produce complete inmunity. This would 
indicate the necessity of establishing a very nice balance between the amounts of immune and virulent blood injected in order to obtain the most perfect results.

During the entire time of immunization the animals were exposed to constant possibility of infection, which may in some degree have influenced our results.

\section{THE CURATIVE EFFECTS OF HOG CHOLERA IMMUNE SERUM.}

Hog No. 118 received on the 17 th day after infection 22 c.c. of the immune serum from hog No.113. This injection of serum had no influence upon the course of the disease, which terminated fatally.

Hog No. 119 received 30 c.c. of the same serum on the 18th day after infection. This produced an immediate fall of temperature. The animal recovered; the value of the serum injection was not apparent.

Hog No. 121 received on the sixth day after infection 20 c.c. of immune serum which produced no noticeable effect either upon the temperature or upon the course of the disease which ended fatally.

Hog No. 125 received 30 c.c. on the eighth day with no effect upon the temperature or the course of the disease.

The administration of immune serum after the sixth day in the amounts given has been wholly without result. What the effect would be when given in larger quantities and earlier in the disease, we have so far made no experiments to determine.

The only record of any previous attempt to immunize hogs by a similar method to be found was that of Preiz, ${ }^{1}$ who by the injection of the serum of a hog, that had recovered from a severe

HOG 131

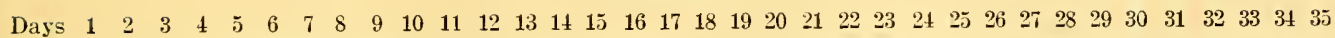

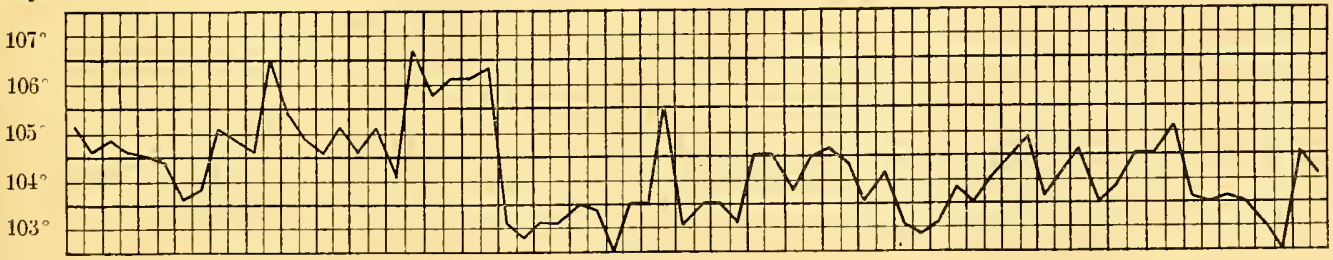

$\wedge$

Vaccinated

attack of hog cholera, into swine already exposed to infection, succeeded in greatly reducing the mortality among them. We were unable to discover any further application of this idea either by Preiz or others.

-1 Ztschr.f. Thiermedicin, 1898, 2, p. 1. 


\section{SUMMARY}

1. Hogs may be immunized against hog cholera by the simultaneous injection of diseased and immune blood, the larger animals with great readiness and apparently without danger, while the smaller animals react more violently and some loss is liable to occur.

2. Drying at $37^{\circ} \mathrm{C}$. or the addition of 33 per cent glycerin does not attenuate the virus sufficiently for immunizing purposes.

3. Moderate doses of immune serum show no curative power. 







